\title{
Antioxidant and Skin Anti-Aging Effects of Marigold Methanol Extract
}

\author{
Chul Ho Kang', Sung Ja Rhie ${ }^{2}$ and Young Chul Kim ${ }^{3}$ \\ ${ }^{1}$ Department of Physical Therapy, Daejeon Woori Hospital, Daejeon, Korea \\ ${ }^{2}$ Department of Beauty Care Design, Halla University, Wonju, Korea \\ ${ }^{3}$ Department of Public Health, Graduate School, Keimyung University, Daegu, Korea
}

\begin{abstract}
The objective of this study was to evaluate the antioxidant and anti-aging effects of marigold methanol extract (MGME) in human dermal fibroblasts. Total polyphenolic and flavonoid contents in MGME were 74.8 mg TAE (tannic acid equivalent)/g and $85.6 \mathrm{mg}$ RE (rutin equivalent)/g, respectively. MGME $(500 \mu \mathrm{g} / \mathrm{mL})$ increased 1,1 diphenyl-2-picryl hydrazyl (DPPH) and 2,2'-azino-3-ethylbenzothiazoline-6-sulfonic acid (ABTS) radical-scavenging, and superoxide dismutase (SOD)-like antioxidant activities by $36.5,54.7$, and $14.8 \%$, respectively, compared with the control. At $1,000 \mu \mathrm{g} / \mathrm{mL}$, these activities increased by $63.7,70.6$, and $20.6 \%$, respectively. MGME $(100 \mu \mathrm{g} / \mathrm{mL})$ significantly increased the synthesis of type 1 procollagen by $83.7 \%$ compared with control treatment. It also significantly decreased Matrix Metalloproteinase-2 (MMP-2) activity and MMP-1 mRNA expression by $36.5 \%$ and $69.5 \%$, respectively; however, it significantly increased laminin- 5 mRNA expression by $181.2 \%$. These findings suggest that MGME could protect human skin against photo-aging by attenuating oxidative damage, suppressing MMP expression and/or activity as well as by stimulating collagen synthesis.
\end{abstract}

Key words: Antioxidant activity, Marigold methanol extract, MMP-1 mRNA, MMP-2 activity, Skin anti-aging effects, Type I procollagen synthesis

\section{INTRODUCTION}

Clinically, photoaging is characterized by wrinkles, laxity, a leathery appearance, increased fragility, blister formation and impaired wound healing. The Matrix Metalloproteinase (MMP)s are a family of zinc-dependent endopeptidases. Although MMP-1 (interstitial collagenase) cleaves collagen type I, MMP-2 is able to degrade elastin as well as basement membrane (BM) compounds including collagen type IV and type VII. MMP-1 is primarily responsible for dermal collagen degradation during the aging process (1), and MMP-2 and MMP-9 degrade the

Correspondence to: Young Chul Kim, Department of Public Health, Graduate School, Keimyung University, Daegu 42601, Korea

E-mail: yckim@kmu.ac.kr

This is an Open-Access article distributed under the terms of the Creative Commons Attribution Non-Commercial License (http:// creativecommons.org/licenses/by-nc/3.0) which permits unrestricted non-commercial use, distribution, and reproduction in any medium, provided the original work is properly cited. extracellular matrix (ECM) proteins that influence skin thickness and wrinkle formation (2).

In vitro studies with cultured human dermal fibroblasts have shown that there is an increase in reactive oxygen species (ROS) production and a reduction in type 1 collagen synthesis when they are exposed to ultraviolet radiation (3). ROS are thought to be a major factor in the destruction of collagen, which is a hallmark of photo-aging (4). The maintenance of the structural integrity of the connection between the epidermis and dermis, called the dermal-epidermal junction, is important to prevent skin aging (5). The BM is a complex multi-molecular structure which firmly attaches the epidermis to the underlying dermis. Laminins are a family of ECM proteins that are localized mainly in BM, and they regulate various cellular functions such as adhesion, motility, growth, differentiation, and apoptosis through interaction with integrins, their specific cell surface receptors (6). Laminin-5 supports cell adhesion and migration more efficiently than other laminins (7).

Retinol, known as vitamin A, has been the focus of attention as an alternative long-term anti-aging agent (8). How- 
ever, it can't be used in general cosmetic formulations due to its instability upon exposure to light, oxygen, heat, lipidperoxidation, or water (9). Retinol also has limited application as a major component of medications and cosmetics because it is fat-soluble and a skin-irritant, causing side-effects such as skin dryness (10). Consequently, there is increasing interest in plant-derived extracts that can induce skin anti-aging effects $(11,12)$.

Tagetes erecta L. is a widespread garden plant that is commonly known as the marigold, and it is widely used as a medicinal herb for its anti-inflammatory, analgesic, and anti-edematous properties, which are important for phytotherapeutic, dermatological and cosmetic applications $(13,14)$. Marigold essential oil has been shown to be an effective free radical scavenger, and the ethanol extract is reportedly effective against parakeratosis $(15,16)$.

In this study, we evaluate the oxidant and anti-aging effects of marigold methanol extract (MGME) by examining collagen synthesis and its degradation, as wells as by examining laminin synthesis in human dermal fibroblasts.

\section{MATERIALS AND METHODS}

Reagents and apparatus. Dimethyl sulfoxide (DMSO), 1,1-diphenyl-2-picryl hydrazyl (DPPH), 2,2'-azino-(3-ethylbenzothiazoline-6-sulfonic acid) (ABTS), tannic acid, ascorbic acid, Folin-Ciocalteu's phenol reagent, and 3(4,5-dimethyl-thiazol-2-yl)-2,5-diphenyl-tetrazolium bromide (MTT) were obtained from Sigma-Aldrich (St. Louis, MO, UK). Dulbecco's modified Eagle's medium (DMEM), fetal bovine serum (FBS), and penicillin/streptomycin (P/ S) were obtained from Lonza (Cascade, MD, USA).

UV irradiation was performed with a UVA sunlamp (Sankyo Denki, Tokyo, Japan) using a UV-radiometer (HD 9021, Delta Ohm, Padova, Italy) to measure the amount applied. Morphological changes were examined and photographed with an Olympus BX51 microscope (Olympus, Tokyo, Japan) and ProRes ${ }^{\circledR}$ C14 plus charge-coupled device camera (Jenoptik Optical Systems, Tokyo, Japan).

Plant material. Methanol extract of the marigold plant (Tagetes erecta L.) was obtained from the Korea Plant Extract Bank (Daejeon, Korea). Whole T. erecta plants were collected at late autumn from Hyeongyeong-myeon, Muan-gun, Jeollanam-do, Korea. Pulverized samples (100 g) were added to a flask and subjected to extraction thrice for $24 \mathrm{hr}$ each time with $1 \mathrm{~L}$ of $100 \%$ methanol at $45^{\circ} \mathrm{C}$. The extract was filtered through filter paper, concentrated using a rotary vacuum evaporator, and dried. The yield of the $T$. erecta methanol extract was $5.05 \%$. This specimen was dissolved in DMSO before use.

Total polyphenol and flavonoid contents. The FolinDenis assay (17) was performed to determine the total polyphenol content of the MGME. One milliliter each of the MGME and Folin reagent were placed in a test tube and allowed to stand for 3 min before adding $1 \mathrm{~mL}$ of $10 \%$ $\mathrm{Na}_{2} \mathrm{CO}_{3}$ and shaking vigorously. The tubes were incubated for $1 \mathrm{hr}$ at $25^{\circ} \mathrm{C}$ before measuring the absorbance at $725 \mathrm{~nm}$. A standard curve was prepared using tannic acid. The total flavonoid content of the MGME was determined by a modified Davis method (18). The MGME $(100 \mu \mathrm{L})$ was placed in a test tube before adding $1 \mathrm{~mL}$ of diethylene glycol reagent and $100 \mu \mathrm{L}$ of $1 \mathrm{~N} \mathrm{NaOH}$. The mixture was shaken vigorously and incubated at $37^{\circ} \mathrm{C}$ for $1 \mathrm{hr}$ before measuring the absorbance at $420 \mathrm{~nm}$. A standard curve was prepared using rutin.

Electron donating ability. The electron donating ability was evaluated as previously described (19). One hundred microliter of MGME dissolved in $0.1 \%$ DMSO at 250,500 , or $1,000 \mu \mathrm{g} / \mathrm{mL}$ was placed in a 96 -well plate before adding $100 \mu \mathrm{L}$ of $0.2 \mathrm{mM}$ DPPH. The mixture was shaken vigorously and incubated for $10 \mathrm{sec}$ at $37^{\circ} \mathrm{C}$ before measuring the absorbance at $517 \mathrm{~nm}$. Catechin was used as the positive control. The DPPH radical scavenging activity of each solution was calculated as the percent of inhibition.

ABTS radical scavenging ability. The ABTS cation decolorization assay (20) was performed with modifications to compare the antioxidant activity of MGME to that of catechin. The ABTS radical cation $\left(\mathrm{ABTS} \bullet^{+}\right)$was produced by reacting a $7 \mathrm{mM}$ ABTS solution with $2.4 \mathrm{mM}$ potassium peroxodisulfate at room temperature in the dark for $12 \mathrm{hr}$, after which it was diluted with ethanol to an absorbance of $0.7 \pm 0.02$ at $734 \mathrm{~nm}$. The samples were diluted to concentrations of $31.25 \sim 1,000 \mu \mathrm{g} / \mathrm{mL}$, and 3 replicates of each were deposited in the wells of a 96-well plate. An equal volume of ABTS $\bullet^{+}$solution was added, and the reaction proceeded for $7 \mathrm{~min}$ in the dark at $25^{\circ} \mathrm{C}$ before measuring the absorbance at $734 \mathrm{~nm}$, which was used to calculate.

Superoxide dismutase (SOD)-like activity. The SODlike activity of MGME and catechin were determined as previously described (21) for solutions of $31.25 \sim 1,000 \mu \mathrm{g} /$ $\mathrm{mL}$. The solution $(0.2 \mathrm{~mL})$ was mixed with $2.6 \mathrm{~mL}$ of Tris-HCl buffer (50 mM Tris, $10 \mathrm{mM}$ EDTA, $\mathrm{pH} 8.5$ ) and incubated at $25^{\circ} \mathrm{C}$ for $10 \mathrm{~min}$, after which $0.1 \mathrm{~mL}$ of $1 \mathrm{M}$ $\mathrm{HCl}$ was added stop the reaction. The absorbance at $420 \mathrm{~nm}$ was measured to determine the amount of oxidized pyrogallol.

Cell culture. The human dermal fibroblasts (passages 10-12) used in this study were kindly provided by the Amore Pacific Co (Yongin, Korea). The cells were grown in DMEM supplemented with $10 \% \mathrm{FBS}$ and $1 \% \mathrm{P} / \mathrm{S}$ in a 
humidified $5 \% \mathrm{CO}_{2}$ atmosphere at $37^{\circ} \mathrm{C}$ for $48 \mathrm{hr}$.

UVA irradiation and sample treatment. The human dermal fibroblasts were cultivated in a culture dish until to being a confluency of approximately $80 \%$. After removing the medium, the cells were washed with PBS. The samples were treated to the cells $\left(1.5 \times 10^{5}\right.$ cells $\left./ \mathrm{mL}\right)$ in the DMEM without FBS before irradiation with $6.3 \mathrm{~J} / \mathrm{cm}^{2}$ UVA followed by cultivation for $24 \mathrm{hr}$, and used for MMP-2 activity and expression of MMP-1 and laminin-5.

MTT assay. Human dermal fibroblasts were placed in the wells $\left(0.5 \times 10^{4}\right.$ cells/well $)$ of a 96 -well plate and incubated in a humidified $5 \% \mathrm{CO}_{2}$ atmosphere at $37^{\circ} \mathrm{C}$ for $24 \mathrm{hr}$. The MGME $(200 \mu \mathrm{L})$ diluted with phenol red-free DMEM (PRF-DMEM) to concentrations of $25 \sim 200 \mu \mathrm{g} /$ $\mathrm{mL}$ was added to the wells, and the plate was incubated for another $48 \mathrm{hr}$. The MTT $(0.5 \mu \mathrm{g} / \mathrm{mL})$ was added to each well and the cells were incubated for a further $3 \mathrm{hr}$. The plate was centrifuged at $1,000 \mathrm{rpm}$ for $10 \mathrm{~min}$, the supernatant was removed, and $200 \mu \mathrm{L}$ of DMSO was added to each well. After dissolving the cells for $15 \mathrm{~min}$ with a plate-shaker, the absorbance at $540 \mathrm{~nm}$ was measured with an ELISA reader.

Morphological observation. The human dermal fibroblasts were treated with MGME at concentrations of $12.5 \sim 200 \mu \mathrm{g} / \mathrm{mL}$, and the cells incubated as described above for $48 \mathrm{hr}$. After changing the medium, the cells were observed microscopically and photographed.

Type I procollagen synthesis assay. Human dermal fibroblasts were treated with MGME at concentrations of $12.5 \sim 100 \mu \mathrm{g} / \mathrm{mL}$, and the supernatants were removed and analyzed with an EIA kit (Takara, Japan). The absorbance at $450 \mathrm{~nm}$ was used to calculate the type 1 procollagen protein yield as described (22), with TGF- $\beta 1$ ( $5 \mathrm{ng} / \mathrm{mL})$ used as the positive control.

The human dermal fibroblasts were stabilized in DMEM containing $10 \% \mathrm{FBS}$ and $1 \% \mathrm{P} / \mathrm{S}$ (DMEM-FBS-P/S) and incubated in a humidified $5 \% \mathrm{CO}_{2}$ atmosphere at $37^{\circ} \mathrm{C}$ for $48 \mathrm{hr}$. The cells were harvested and divided into the wells of a 12 -well plate in a $500 \mu \mathrm{L}$ volume with $0.7 \times 10^{5}$ cells/ well and incubated for $24 \mathrm{hr}$. After removing the medium, the cells were washed twice with PBS, and $1 \mathrm{~mL}$ of PRFDMEM with $1 \% \mathrm{P} / \mathrm{S}$ was added before incubating a further $24 \mathrm{hr}$. The cells were washed with PBS-P/S, and 1.5 $\mathrm{mL}$ of PRF-DMEM containing $0.1 \%$ DMSO and MGME at concentrations of $12.5 \sim 100 \mu \mathrm{g} / \mathrm{mL}$ was added. The cells were incubated for $48 \mathrm{hr}$, and the supernatants were obtained by centrifugation for $10 \mathrm{~min}$ at $12,000 \mathrm{rpm}$ for use as the sample for the procollagen protein quantitative analysis. The antibody-peroxidase-conjugate solution (100 $\mu \mathrm{L}$ ) was placed into the wells of a 96-well EIA kit and
$20 \mu \mathrm{L}$ of the 4-fold diluted samples were added. The kit was wrapped in foil and incubated at $37^{\circ} \mathrm{C}$ for $3 \mathrm{hr}$.

The cells were washed 4 times with PBS, $100 \mu \mathrm{L}$ of the substrate solution was added, and the foil-wrapped kit was incubated at room temperature for $15 \mathrm{~min}$. The stop solution $\left(100 \mu \mathrm{L}\right.$ of $\left.1 \mathrm{~N} \mathrm{H}_{2} \mathrm{SO}_{4}\right)$ was added and the absorbance at $450 \mathrm{~nm}$ was measured 3 times with an ELISA reader. The procollagen protein yield was separated from the protein content as described (23) and quantified with bovine serum albumin (BSA) standards. Cell lysis buffer $(80 \mu \mathrm{L}$; CelLytic $^{\mathrm{TM}}$ B Cell Lysis Reagent, Sigma-Aldrich, St. Louis, MO, USA) was added to the plate, and frozen $\left(-20^{\circ} \mathrm{C}\right)$ and thawed 3 times before removing the mixture from the plate. The protein content of 1/10 dilution of the freeze-thawed mixture was quantified using the BSA standard curve.

MMP-2 activity. The samples were adjusted to contain the same amount of protein and mixed with an equal volume of $2 \times$ sample buffer to be a $30 \mu \mathrm{L}$ of composites, incubated at the room temperature for $10 \mathrm{~min}$, and loaded onto a 10\% zymogram gel (Invitrogen, Carlsbad, CA, USA). After electrophoretic separation, the gel was incubated with Novex zymogram renaturing buffer for $30 \mathrm{~min}$, Novex zymogram developing buffer for $30 \mathrm{~min}$, and with fresh developing buffer for $24 \mathrm{hr}$ at $37^{\circ} \mathrm{C}$. The gel was incubated with Simply Blue ${ }^{\mathrm{TM}}$ Safe Stain (Invitrogen), washed with sterile distilled water, and MMP-2 activity was quantified with an image analyzer.

MMP-1 expression. The total RNA from human dermal fibroblasts was extracted with $1 \mathrm{~mL}$ of TRIzol (Invitrogen, USA) per the manufacturer instructions, and $5 \mu \mathrm{g}$ samples were reverse transcribed in $40 \mu \mathrm{L}$ of reactions containing $8 \mu \mathrm{L}$ of $5 \times$ M-MLV RT (Murine Leukemia Virus Reverse Transcriptase) buffer, $3 \mu \mathrm{L}$ dNTPs (10 mM), $0.45 \mu \mathrm{L}$ RNasein $(40 \mathrm{U} / \mu \mathrm{L}), 0.3 \mu \mathrm{L}$ M-MLV reverse transcriptase (200 U/ $\mu \mathrm{L}$; Promega, Madison, WI, USA), and $3.75 \mu \mathrm{L}$ of oligo dT $(20 \mathrm{pmol} / \mu \mathrm{L}$; Bioneer, Korea $)$. Single stranded cDNA was amplified by PCR using $4 \mu \mathrm{L}$ of $5 \times$ Green Go-Taq ${ }^{\circledR}$ Flexi reaction buffer, $0.4 \mu \mathrm{L}$ dNTPs $(10$ $\mathrm{mM}), 0.1 \mu \mathrm{L}$ Taq polymerase $(5 \mathrm{U} / \mu \mathrm{L}), 1.2 \mu \mathrm{L} \mathrm{MgCl}_{2}(25$ $\mathrm{mM}$; Promega, USA), and $0.4 \mu \mathrm{L}$ each $(20 \mathrm{pmol} / \mu \mathrm{L})$ of specific sense and anti-sense primers for MMP-1 or $\beta$ actin. The PCR primer sequences were as follows: MMP1 forward, 5'-AAA GGG AAT AAG TAC TGG GC-3', and reverse, 5'-AAT TCC AGG AAA GTC ATG TG-3'; and $\beta$-actin forward, 5'-ATG CAG AAG GAG ATC ACT GC-3', and reverse, 5'-CTG CGC AAG TTA GGT TTT GT-3'. The expected size of the amplified MMP-1 and $\beta$ actin products were 237 and 248 base pairs, respectively. The PCR conditions were 28 cycles of $94^{\circ} \mathrm{C}$ for $60 \mathrm{sec}$, $50^{\circ} \mathrm{C}$ for $60 \mathrm{sec}$, and $72^{\circ} \mathrm{C}$ for $60 \mathrm{sec}$. The PCR products were run on a $1.2 \%$ agarose gel, with $\beta$-actin acting as an internal control to evaluate the relative expression of MMP-1. 
Laminin-5 expression. The total RNA was isolated from human dermal fibroblasts, reverse transcribed with specific sense and anti-sense primers for laminin-5 or $\beta$ actin, and amplified as described above. The PCR primer sequences were as follows: laminin-5 forward, 5'-GAC TGC CTG CTG TGC CAG C-3', and reverse, 5'-GGG GTA GCC ATG AAA GCC CG-3'; and $\beta$-actin forward, 5'-ATG CAG AAG GAG ATC ACT GC-3', and reverse, 5'-CTG CGC AAG TTA GGT TTT GT-3'. The expected size of the amplified laminin-5 and $\beta$-actin products were 195 and 248 base pairs, respectively. The PCR condition was 35 cycles of $94^{\circ} \mathrm{C}$ for $45 \mathrm{sec}, 60^{\circ} \mathrm{C}$ for $45 \mathrm{sec}$, and $72^{\circ} \mathrm{C}$ for $60 \mathrm{sec}$. The amplification products were run on a $1.5 \%$ agarose gel and visualized with ethidium bromide staining. The DNA band densities were evaluated with the KODAK Gel Logic 100 image analysis system (Eastman Kodak Co., Rochester, NY, USA).

Statistical analysis. The difference in values between groups was statistically evaluated with one-way analyses of variance (ANOVA) followed by post-hoc Duncan multiple range tests using SPSS 18.0 statistical software (SPSS Inc., Chicago, IL, USA). Differences were considered statistically significant for $p<0.05$.
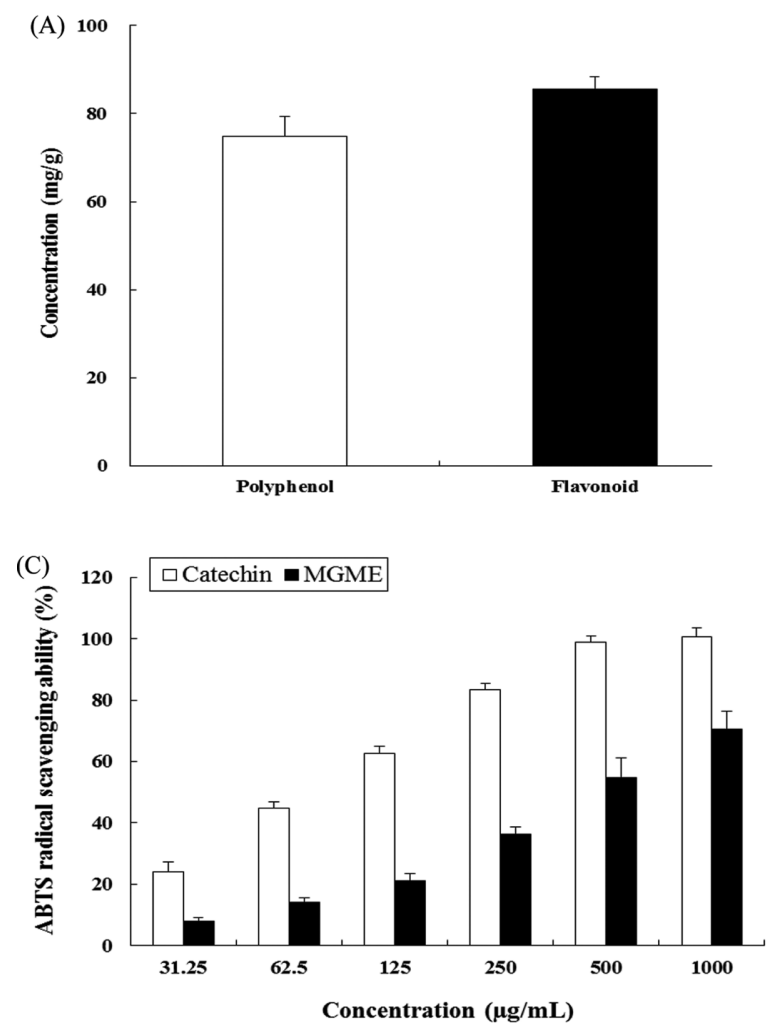

\section{RESULTS}

Antioxidant activities of MGME. The total content of the antioxidants polyphenol and flavonoid in MGME was $74.8 \mathrm{mg}$ TAE (tannic acid equivalent)/g and $85.6 \mathrm{mg}$ $\mathrm{RE}$ (rutin equivalent)/g, respectively (Fig. 1A). The electron donating ability of MGME at 500 and $1,000 \mu \mathrm{g} / \mathrm{mL}$ was $36.5 \%$ and $63.7 \%$, respectively; these values were lower than for the control catechin at the same concentrations, which were $87.9 \%$ and $97.8 \%$, respectively (Fig. 1B). The ABTS radical scavenging ability of MGME at 500 and $1,000 \mu \mathrm{g} / \mathrm{mL}$ was $54.7 \%$ and $70.6 \%$, respectively; these values were lower than for the control catechin $(98.8 \%$ and $100.7 \%$, respectively; Fig. 1C). The SOD-like activity of MGME at 500 and $1,000 \mu \mathrm{g} / \mathrm{mL}$ was $14.8 \%$ and $20.6 \%$, respectively, which was lower than for catechin $(22.8 \%$ and $30.0 \%$, respectively; Fig. 1D). Together, these results indicate that MGME has lower antioxidant activities than the control compound catechin.

Human dermal fibroblast viability. The MTT assay was used to determine the maximum permissible level (MPL) of MGME in human dermal fibroblasts. MGME
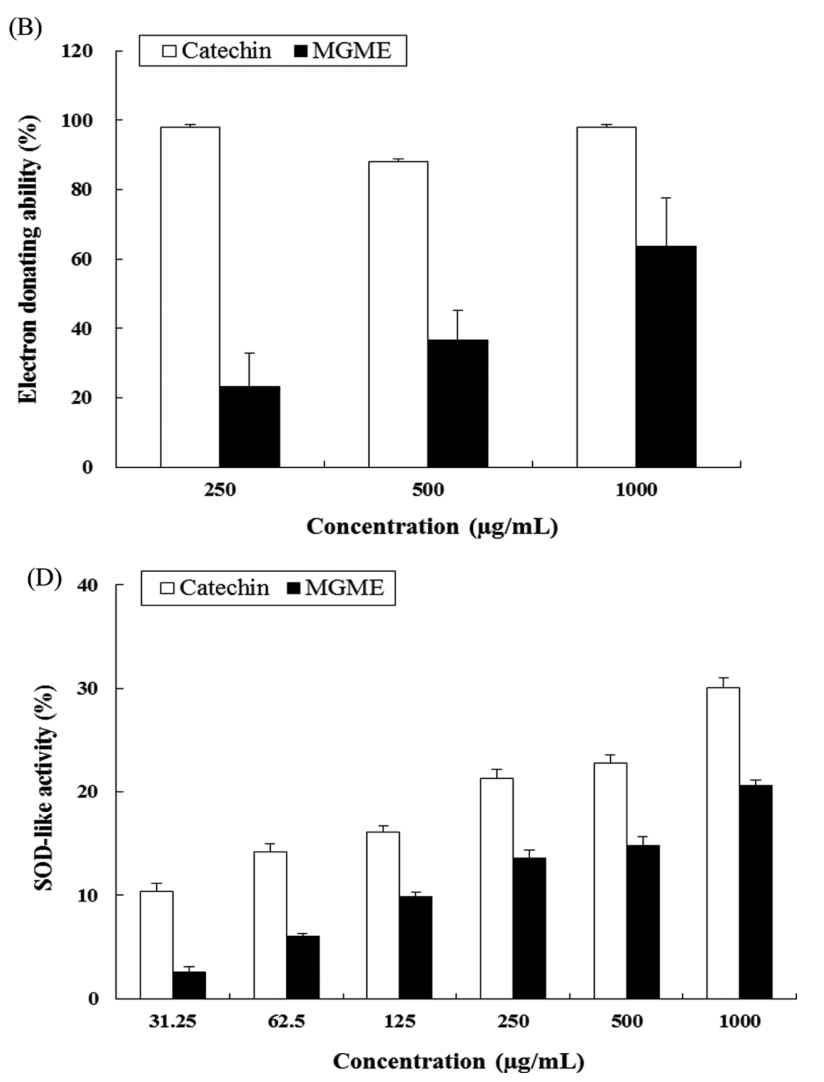

Fig. 1. Antioxidant activity of marigold methanol extract (MGME). (A) Total polyphenol and flavonoid contents, (B) Electron donating ability, (C) ABTS radical scavenging ability, (D) SOD-like activity. Bars represent mean $\pm S D(n=3)$. 


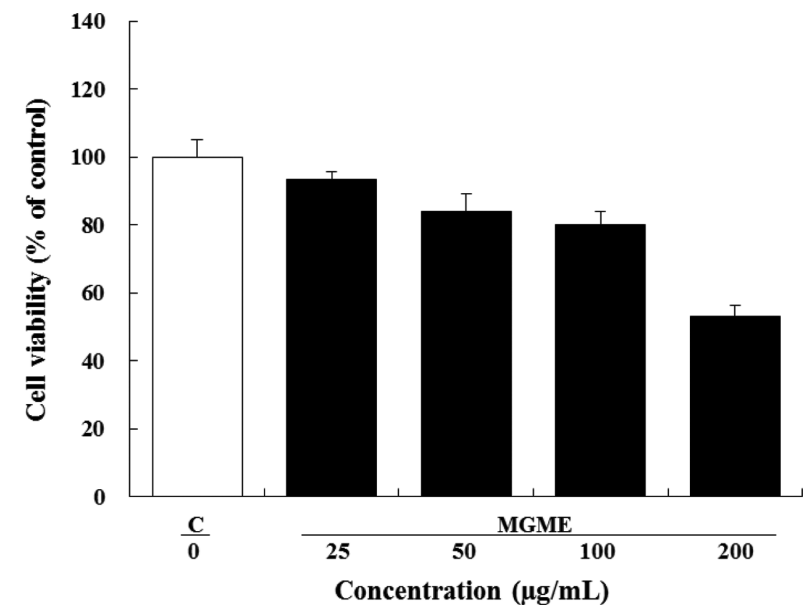

Fig. 2. Effect of MGME on cell viability. Human dermal fibroblasts were treated with indicated concentrations of MGME or vehicle (control, C). Bars represent mean $\pm S D(n=3)$.

treatments at concentrations of 100 and $200 \mu \mathrm{g} / \mathrm{mL}$ reduced cell viability by $19.8 \%$ and $46.8 \%$, respectively, compared to vehicle-treated cells, corresponding to an MPL of 100 $\mu \mathrm{g} / \mathrm{mL}$ (Fig. 2).
Morphological observation of human dermal fibroblasts. Fibroblasts treated with low or intermediate concentrations of MGME (Fig. 3B-3E) maintained the flat, spindle-like shape observed in vehicle-treated control cells (Fig. 3A); however, at a concentration of $200 \mu \mathrm{g} / \mathrm{mL}$, cells had irregular or rounded shape, and the cell density was decreased (Fig. 3F).

Type I procollagen synthesis. MGME treatment at concentrations of 25,50 , and $100 \mu \mathrm{g} / \mathrm{mL}$ led to significant $(p<0.05)$ increase in collagen production by $43.5 \%$, $55.8 \%$, and $83.7 \%$, respectively, compared to DMSOtreated control cells (Fig. 4).

MMP activity and expression. MGME treatment resulted in a decreased MMP-2 protein expression, as observed by zymography (Fig. 5A). At concentrations of $12.5,25,50$, and $100 \mu \mathrm{g} / \mathrm{mL}, \mathrm{MMP}-2$ activity was significantly $(p<0.05)$ decreased by $28.8 \%, 31.8 \%, 33.5 \%$, and $36.5 \%$, respectively, compared to UVA-irradiated control cells (Fig. 5B). In addition, at these concentrations, $M M P-1$ transcript levels were significantly $(p<0.05)$ reduced in a dose-dependent manner by $50.3 \%, 51.5 \%, 60.2 \%$, and
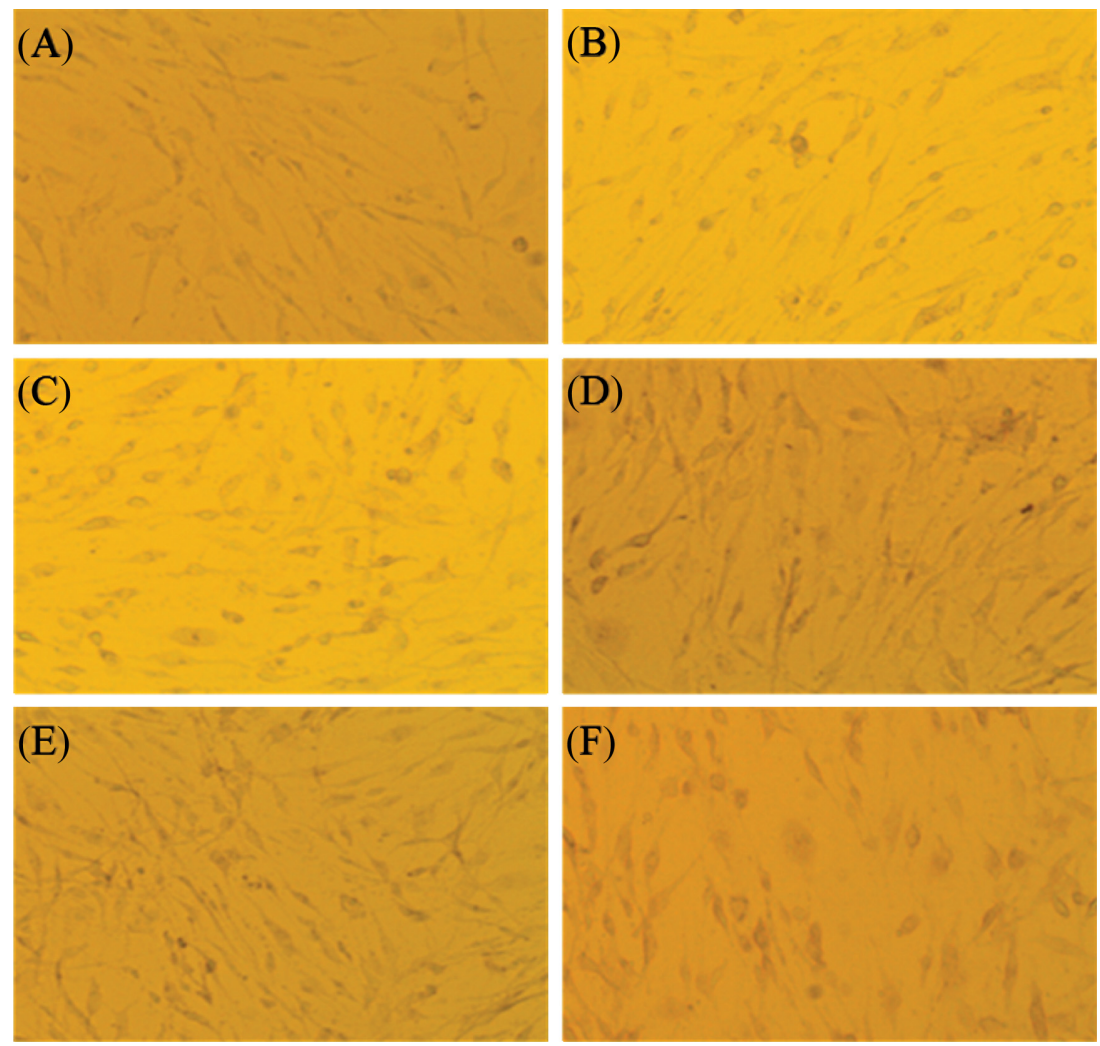

Fig. 3. Morphological changes in human dermal fibroblasts upon treatment with MGME. (A) DMSO-treated control cells were flat, with spindle-like morphology; MGME concentrations of (B) 12.5 , (C) 25 , (D) 50 , or (E) $100 \mu \mathrm{g} / \mathrm{mL}$ had no effect on cell morphology, but at a concentration of (F) $200 \mu \mathrm{g} / \mathrm{mL}$, cells were frequently observed to have a rounded, irregular shape and were clustered. $200 \times$ magnification. 




Fig. 4. Effect of MGME on collagen production in human dermal fibroblasts. Cells were treated with the vehicle DMSO, $5 \mathrm{ng} / \mathrm{mL}$ TGF- $\beta 1$ (positive control, PC), or MGME at the indicated concentrations, and the production of procollagen was measured by ELISA. Bars represent mean $\pm S D(n=3)$. Statistically significant differences, as determined by ANOVA and the Duncan multiple range test, are indicated by different letters $(p<0.05, \mathrm{a}<\mathrm{b}<\mathrm{c}<\mathrm{d})$.

\section{(A)}

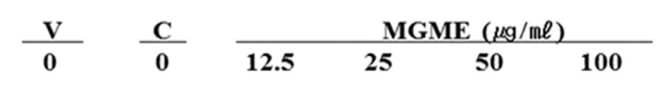

\section{MMP-2}

(B)

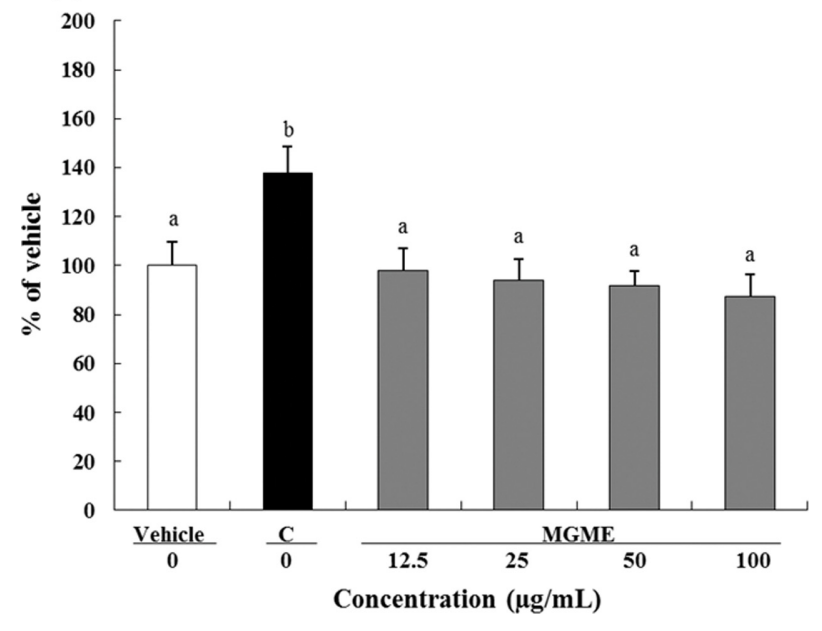

Fig. 5. Effect of MGME on MMP-2 activity in human dermal fibroblasts. (A) MMP-2 protein expression decreased upon treatment with MGME in a dose-dependent manner compared to UVA-irradiated control cells (C). (B) Quantification of MMP-2 activity in cells treated with the vehicle DMSO, $6.3 \mathrm{~J} / \mathrm{cm}^{2}$ UVA radiation (C), or MGME at the indicated concentrations. Bars represent mean $\pm S D(n=3)$. Statistically significant differences, as determined by ANOVA and the Duncan multiple range test, are indicated by different letters $(p<0.05, a<b)$.
(A)
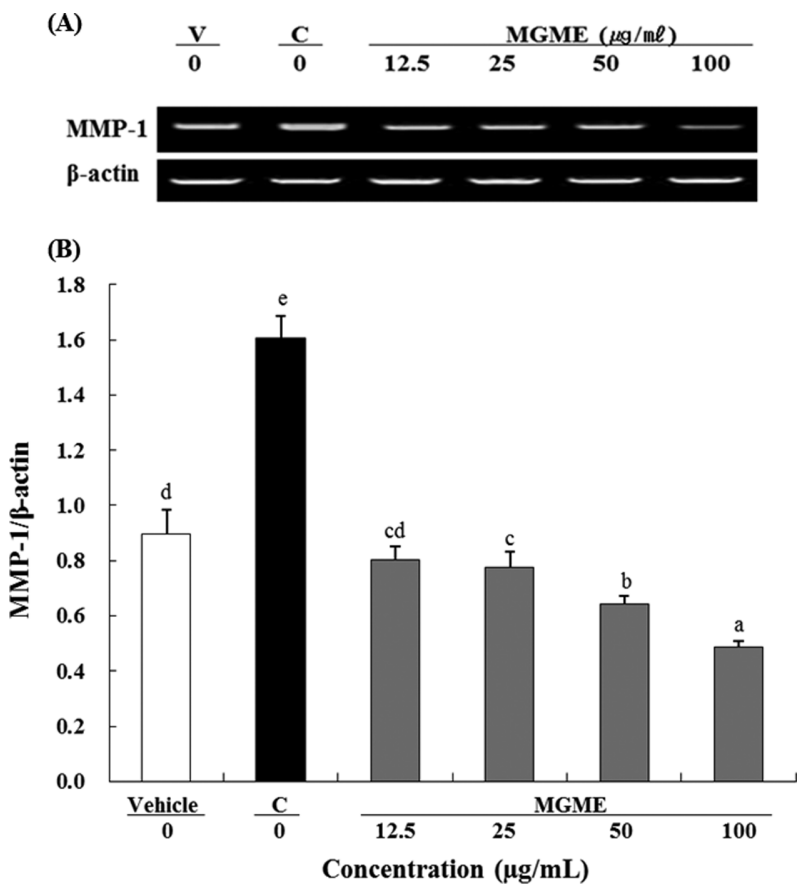

Fig. 6. Effect of MGME on MMP-1 mRNA expression in human dermal fibroblasts. (A) MMP-1 transcript levels decreased upon treatment with MGME in a dose-dependent manner compared to UVA-irradiated control cells (C), as determined by RTPCR. Expression was normalized to $\beta$-actin levels. (B) Quantification of MMP-1 transcript expression in cells treated with the vehicle DMSO, $6.3 \mathrm{~J} / \mathrm{cm}^{2}$ UVA radiation (C), or MGME at the indicated concentrations. Bars represent mean $\pm S D(n=3)$. Statistically significant differences, as determined by ANOVA and the Duncan multiple range test, are indicated by different letters $(p<0.05, a<b<c<d<e)$.

69.5\%, respectively, as determined by RT-PCR (Fig. 6).

Laminin-5 mRNA expression. Treatments of cells with MGME at $12.5,25,50$, and $100 \mu \mathrm{g} / \mathrm{mL}$ significantly $(p<0.05)$ increased laminin-5 mRNA expression in a dose-dependent manner by $40.6 \%, 106.2 \%, 143.7 \%$, and $181.2 \%$, respectively, compared to UVA-irradiated control cells, as determined by RT-PCR (Fig. 7). Taken together, these results indicate that exposure of human dermal fibroblasts to MGME decreases cell viability, reduces MMP expression and its enzyme activity, it increases the expression of matrix components laminin-5 as well as collagen production.

\section{DISCUSSION}

Antioxidant phenolic compounds have anti-aging effects on the skin (24). Polyphenols exhibit excellent anti-inflammatory, anti-bacterial, and UV-protective properties (25). Flavonoids are potent antioxidants comprising naturally occurring plant phenolic compounds, including flavones, 

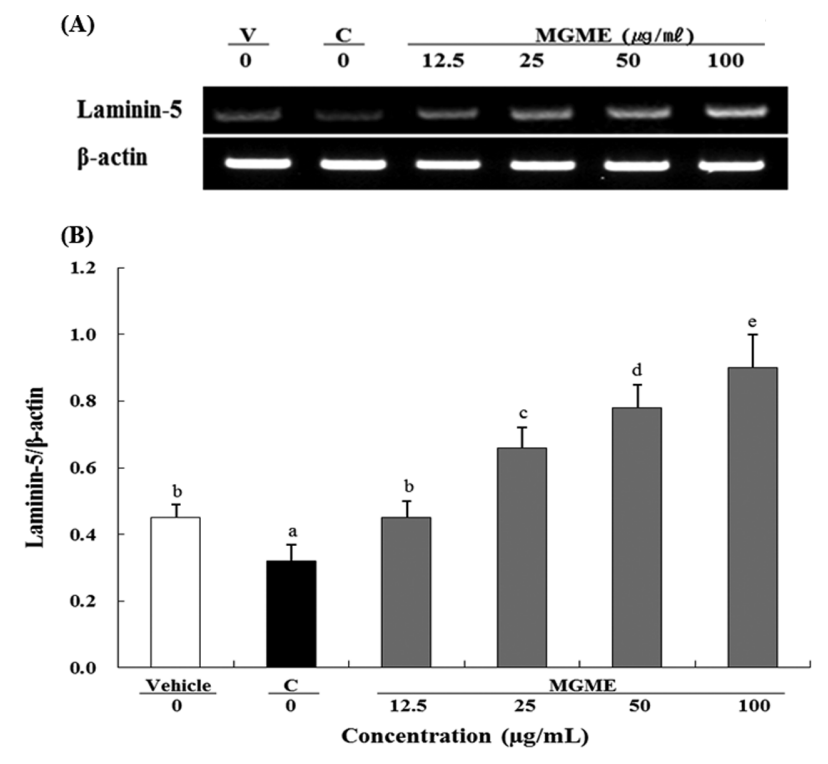

Fig. 7. Effect of MGME on laminin-5 mRNA expression in human dermal fibroblasts. (A) Laminin-5 transcript levels increased upon treatment with MGME in a dose-dependent manner compared to UVA-irradiated control cells (C), as determined by RT-PCR. Expression was normalized to $\beta$-actin levels. (B) Quantification of Laminin-5 transcript expression in cells treated with the vehicle DMSO, $6.3 \mathrm{~J} / \mathrm{cm}^{2}$ UVA radiation (C), or MGME at the indicated concentrations. Bars represent mean \pm $S D(n=3)$. Statistically significant differences, as determined by ANOVA and the Duncan multiple range test, are indicated by different letters $(p<0.05, \mathrm{a}<\mathrm{b}<\mathrm{c}<\mathrm{d}<\mathrm{e})$.

flavonols, isoflavones, flavonones, and chalcones (26). These compounds are known to be the main components of $T$. erecta L (27). In this study, the total polyphenol and flavonoid contents of MGME were $74.8 \mathrm{mg} \mathrm{TAE} / \mathrm{g}$ and $85.6 \mathrm{mg} \mathrm{RE} / \mathrm{g}$, respectively; we observed a higher total flavonoid content in the methanol extract of whole Korean marigold plant than that $(68.9 \mathrm{mg} \mathrm{RE} / \mathrm{g})$ reported by Kaisoon et al. for a methanol extract from Thai marigold flower (28). Li et al. reported that total flavonoid contents in the ethanol extracts from eleven different cultivars of Chinese marigold flower varied from 28.6 to $93.3 \mathrm{mg}$ RE/ $\mathrm{g}$ (29). Therefore, we propose that differences in the cultivar, plant parts, and extraction solvent contribute to the difference in flavonoid content observed in this study.

The DPPH assay is an easy colorimetric method routinely utilized for assessing the free radical-scavenging potential of an antioxidant molecule (30). The ABTS method is also used to determine the antioxidant activity of both lipophilic and hydrophilic antioxidants in various matrices (31). In this study, MGME $(1,000 \mu \mathrm{g} / \mathrm{mL})$ exhibited free radical-scavenging capacities of $63.7 \%$ (DPPH assay) and $70.6 \%$ (ABTS assay). The DPPH radical-scavenging capacity of the soluble phenolic fraction is reported to be $94.3 \%$ in T. erecta L. (28); however, it is reported to vary between 39.4 and $93 \%$ in the ethanol extracts from eleven different cultivars of Chinese marigold flower (29). The essential oil derived from the flowers of T. erecta $\mathrm{L}$. $(100 \mu \mathrm{g} / \mathrm{mL})$ exhibits DPPH and ABTS radical-scavenging capacities of 71.5 and $57.3 \%$, respectively (32). SOD is an antioxidant enzyme family including metal-containing enzymes that act as a chief ROS scavenger in the cell (33). In this study, MGME $(1,000 \mu \mathrm{g} / \mathrm{mL})$ exhibited an SOD-like activity of $20.6 \%$. From the above results, we found that MGME has a potent free radical-scavenging capacity that contributes to its antioxidant effects.

Cytotoxicity of MGME against human dermal fibroblasts was determined by the MTT assay, and the MPL was determined to be $100 \mu \mathrm{g} / \mathrm{mL}$. The dermis contains $85 \sim 90 \%$ type 1 collagen. Procollagen (collagen precursor) is synthesized in dermal fibroblasts in the form of polypeptide chains of type 1 collagen (34). UV irradiation impairs collagen synthesis, primarily through the downregulation of type 1 procollagen expression (34). Topical treatment with $0.05 \%$ all-trans retinoic acid for 10 weeks in non-irradiated hairless mice is reported to increase the amount of type 1 collagen in the skin by $22 \%$ compared with vehicle treatment (35). In this study, collagen production significantly increased by $83.7 \%$ in MGME $(100 \mu \mathrm{g} /$ $\mathrm{mL}$ )-treated fibroblasts compared to that in control fibroblasts, indicating that MGME is a potent inducer of collagen synthesis.

UV light is known to induce the expression of MMP-1, -2 , and -9 in normal human epidermis in vivo (36), and MMP inhibition may be a promising strategy to prevent photo-aging (37). MMP-1 acts as a primary mediator of UVB-induced skin damage and premature aging (1). In this study, MGME $(100 \mu \mathrm{g} / \mathrm{mL})$ significantly decreased the expression of $M M P-1$ mRNA by $69.5 \%$ in human dermal fibroblasts compared with control treatment. MGME significantly inhibits hyaluronidase $\left(\mathrm{IC}_{50}\right.$ of $\left.11.70 \mu \mathrm{g} / \mathrm{mL}\right)$ and elastase $\left(\mathrm{IC}_{50}\right.$ of $\left.4.13 \mu \mathrm{g} / \mathrm{mL}\right)$ activities and $M M P-1$ expression to a greater extent than oleanolic acid (38). Chronic UVB exposure increases skin MMP-2 levels as measured by gelatin zymography (2). In this study, MGME $(100 \mu \mathrm{g} / \mathrm{mL})$ significantly decreased MMP-2 activity by $36.5 \%$ in human dermal fibroblasts compared with control treatment. Based on its effect on MMP, MGME acts as a potent collagen degradation inhibitor.

Laminin-5, present in the BM, initiates hemidesmosome formation to facilitate attachment of the epidermis to the dermis, and maintains structural integrity of cells and physiological homeostasis of the skin (39). Consequently, increased laminin-5 expression rejuvenates the aged skin (40). In this study, laminin-5 expression significantly increased by $181.2 \%$ in MGME $(100 \mu \mathrm{g} / \mathrm{mL})$-treated human dermal fibroblasts compared to that in vehicle-treated fibroblasts, indicating that MGME holds remarkable skin anti-aging potential. 
Results of this study indicate that MGME, owing to the high levels of polyphenols, induces collagen synthesis and inhibits its degradation in human dermal fibroblasts. These findings suggest that MGME could protect human skin against photo-aging by suppressing MMP expression and/ or activity as well as by stimulating collagen synthesis. Therefore, we conclude that MGME has significant skin anti-aging potential.

Received August 21, 2017; Revised September 29, 2017; Accepted October 16, 2017

\section{REFERENCES}

1. Brennan, M., Bhatti, H., Nerusu, K.C., Bhagavathula, N., Kang, S., Fisher, G.J., Varani, J. and Voorhees, J.J. (2003) Matrix metalloproteinase-1 is the major collagenolytic enzyme responsible for collagen damage in UV-irradiated human skin. Photochem. Photobiol., 78, 43-48.

2. Inomata, S., Matsunaga, Y., Amano, S., Takada, K., Kobayashi, K., Tsunenaga, M., Nishiyama, T., Kohno, Y. and Fukuda, M. (2003) Possible involvement of gelatinases in basement membrane damage and wrinkle formation in chronically ultraviolet B-exposed hairless mouse. J. Invest. Dermatol., 120, 128-134.

3. Buechner, N., Schroeder, P., Jakob, S., Kunze, K., Maresch, T., Calles, C., Krutmann, J. and Haendeler, J. (2008) Changes of MMP-1 and collagen type I alpha1 by UVA, UVB and IRA are differentially regulated by Trx-1. Exp. Gerontol., 43, 633-637.

4. Dong, K.K., Damaghi, N., Picart, S.D., Markova, N.G., Obayashi, K., Okano, Y., Masaki, H., Grether-Beck, S., Krutmann, J., Smiles, K.A. and Yarosh, D.B. (2008) UVinduced DNA damage initiates release of MMP-1 in human skin. Exp. Dermatol., 17, 1037-1044.

5. Amano, S., Ogura, Y., Akutsu, N., Matsunaga, Y., Kadoya, K., Adachi, E. and Nishiyama, T. (2005) Protective effect of matrix metalloproteinase inhibitors against epidermal basement membrane damage: skin equivalents partially mimic photoaging process. Br. J. Dermatol., 153, 37-46.

6. Aumailley, M. and Rousselle, P. (1999) Laminins of the dermo-epidermal junction. Matrix Biol., 18, 19-28.

7. Miyazaki, K., Kikkawa, Y., Nakamura, A., Yasumitsu, H. and Umeda, M. (1993) A large cell-adhesive scatter factor secreted by human gastric carcinoma cells. Proc. Natl. Acad. Sci. U.S.A., 90, 11767-11771.

8. Varani, J., Warner, R.L., Gharaee-Kermani, M., Phan, S.H., Kang, S., Chung, J.H., Wang, Z.Q., Datta, S.C., Fisher, G.J. and Voorhees, J.J. (2000) Vitamin A antagonizes decreased cell growth and elevated collagen-degrading matrix metalloproteinases and stimulates collagen accumulation in naturally aged human skin. J. Invest. Dermatol., 114, 480-486.

9. Brisaert, M. and Plaizier-Vercammen, J. (2000) Investigation on the photostability of a tretinoin lotion and stabilization with additives. Int. J. Pharm., 199, 49-57.

10. Kim, B.H., Lee, Y.S. and Kang, K.S. (2003) The mechanism of retinol-induced irritation and its application to antiirritant development. Toxicol. Lett., 146, 65-73.
11. Hwang, J.Y., Lee, C.M. and Kim, Y.C. (2015) Anti-wrinkle efficacy of Stachys riederi var. japonica ethanol extract in human dermal fibroblasts. J. Invest. Cosmetol., 11, 293-301.

12. Kim, S.E., Lee, C.M. and Kim, Y.C. (2016) Anti-wrinkle efficacy of Oenothera laciniata methanol extract in human dermal fibroblasts. J. Invest. Cosmetol., 12, 197-203.

13. Hamburger, M., Adler, S., Baumann, D., Förg, A. and Weinreich, B. (2003) Preparative purification of the major antiinflammatory triterpenoid esters from Marigold (Calendula officinalis). Fitoterapia, 74, 328-338.

14. Bashir, S. and Gilani, A.H. (2008) Studies on the antioxidant and analgesic activities of Aztec marigold (Tagetes erecta) flowers. Phytother. Res., 22, 1692-1694.

15. Khan, M.T. and Evans, F.J. (1996) Clinical evaluation of Tagetes erecta in the treatment of parakeratosis. Phytother. Res., 10, 186-188.

16. Gutiérrez, R.M.P., Luna, H.H. and Garrido, S.H. (2006) Antioxidant activity of Tagetes erecta essential oil. J. Chil. Chem. Soc., 51, 883-886.

17. Folin, O. and Denis, W. (1912) On phosphotungstic-phosphomolybdic compounds as color reagents. J. Biol. Chem., 12, 239-249.

18. Davis, R., Massey, R.C. and Mcweeny, D.J. (1980) The catalysis of the $N$-nitrosation of secondary amines by nitrosophenols. J. Food Chem., 6, 115-122.

19. Pérez, G.R.M., Vargas, S.R., Martinez, M.F.J. and Cordova, R.I. (2004) Antioxidant and free radical scavenging activities of 5,7,3'-trihydroxy-3,6,4'-trimethoxyflavone from Brickellia veronicaefolia. Phytother. Res.,18, 428-430.

20. Re, R., Pellegrini, N., Proteggente, A., Pannala, A., Yang, M. and Rice-Evans, C. (1999) Antioxidant activity applying an improved ABTS radical cation decolorization assay. Free Radic. Biol. Med., 26, 1231-1237.

21. Marklund, S. and Marklund, G. (1974) Involvement of the superoxide anion radical in the autoxidation of pyrogallol and a convenient assay for superoxide dismutase. Eur. $J$. Biochem., 47, 469-474.

22. Son, E.D., Choi, G.H., Kim, H., Lee, B., Chang, I.S. and Hwang, J.S. (2007) Alpha-ketoglutarate stimulates procollagen production in cultured human dermal fibroblasts, and decreases UVB-induced wrinkle formation following topical application on the dorsal skin of hairless mice. Biol. Pharm. Bull., 30, 1395-1399.

23. Lowry, O.H., Rosebrough, N.J., Farr, A.L. and Randall, R.J. (1951) Protein measurement with the Folin phenol reagent. J. Biol. Chem., 193, 265-275.

24. Dudonné, S., Vitrac, X., Coutière, P., Woillez, M. and Mérillo, J.M. (2009) Comparative study of antioxidant properties and total phenolic content of 30 plant extracts of industrial interest using DPPH, ABTS, FRAP, SOD, and ORAC assays. J. Agric. Food Chem., 57, 1768-1774.

25. Lee, C.J., Chen, L.G., Chang, T.L., Ke, W.M., Lo, Y.F. and Wang, C.C. (2011) The correlation between skin-care effects and phytochemical contents in Lamiaceae plants. Food Chem., 124, 833-841.

26. Pokorny, J., Yanishlieva, N. and Gordon, M. (2001) Antioxidants in food: practical applications. Woodhead Publishing Limited, Cambridge, pp. 22-70.

27. Xu, L.W., Juan, C., Qi, H.Y. and Shi, Y.P. (2012) Phyto- 
chemicals and their biological activities of plants in Tagetes L. Chinese Herbal Medicines, 4, 103-117.

28. Kaisoon, O., Siriamornpun, S., Weerapreeyakul, N. and Meeso, N. (2011) Phenolic compounds and antioxidant activities of edible flowers from Thailand. J. Funct. Foods, 3, 88-99.

29. Li, W., Gao, Y., Zhao, J. and Wang, Q. (2007) Phenolic, flavonoid and lutein ester content and antioxidant activity of 11 cultivars of Chinese marigold. J. Agric. Food Chem., 55, 8478-8484.

30. Mishra, K., Ojha, H. and Chaudhury, N.K. (2012) Estimation of antiradical properties of antioxidants using DPPH assay: a critical review and results. Food Chem., 130, 10361043.

31. Cano, A., Acosta, M. and Arnaro, M.B. (2000) A method to measure antioxidant activity in organic media: application to lipophilic vitamins. Redox Rep., 5, 365-370.

32. Gutiérrez, R.M.P., Luna, H.H. and Garrido, S.H. (2006) Antioxidant activity of Tagetes erecta essential oil. J. Chil. Chem. Soc., 51, 883-886.

33. Chen, X., Zhang, E., Fang, L., Zhang, J., Zhu, J., He, W. and Luo, X. (2013) Repair effects of exogenous SOD on Bacillus subtilis against gamma radiation exposure. J. Environ. Radioact., 126, 259-263.

34. Fisher, G.J., Kang, S., Varani, J., Bata-Csorgo, Z., Wan, Y.,
Datta, S. and Voorhees, J.J. (2002) Mechanisms of photoaging and chronological skin aging. Arch. Dermatol., 138, 1462-1470.

35. Chaqour, B., Seité, S., Coutant, K., Fourtanier, A., Borel, J.P. and Bellon, G. (1995) Chronic UVB- and all-trans retinoicacid-induced qualitative and quantitative changes in hairless mouse skin. J. Photochem. Photobiol. B, 28, 125-135.

36. Chung, J.H. (2003) Photoaging in Asians. Photodermatol. Photoimmunol. Photomed., 19, 109-121.

37. Moon, H.J., Lee, S.R., Shim, S.N., Jeong, S.H., Stonik, V.A., Rasskazov, V.A., Zvyagintseva, T. and Lee, Y.H. (2008) Fucoidan inhibits UVB-induced MMP-1 expression in human skin fibroblasts. Biol. Pharm. Bull., 31, 284-289.

38. Maity, N., Nema, N.K., Abedy, M.K., Sarkar, B.K. and Mukherjee, P.K. (2011) Exploring Tagetes erecta Linn flower for the elastase, hyaluronidase and MMP-1 inhibitory activity. J. Ethnopharmacol., 137, 1300-1305.

39. Schneider, H., Mühle, C. and Pacho, F. (2007) Biological function of laminin-5 and pathogenic impact of its deficiency. Eur. J. Cell Biol., 86, 701-717.

40. Seo, M.Y., Chung, S.Y., Choi, W.K., Seo, Y.K., Jung, S.H., Park, J.M., Seo, M.J., Park, J.K., Kim, J.W. and Park, C.S. (2009) Anti-aging effect of rice wine in cultured human fibroblasts and keratinocytes. J. Biosci. Bioeng., 107, 266271. 